\title{
The Research Fronts of Financial Market Risk Prevention in the Background of Big Data Analysis: Scientific Measurement Analysis from Multidisciplinary Literature
}

\author{
Chung-Lien $\operatorname{Pan}^{1}$ Zizhen Chen $^{1 *}$, Xiaobing Zhou ${ }^{1}$, Jingjing Qiu ${ }^{1}$, YingZhou ${ }^{1}$ \\ ${ }^{1}$ Nanfang College of Sun Yat-sen University School of Accounting Guangzhou, Guangdong
}

\begin{abstract}
Risks are ubiquitous in financial markets, and the occurrence of financial crises has never stopped. In order to provide research fronts for financial market risk prevention in the context of big data analysis, this article is based on 556 articles retrieved from the Web of Science database. Keywords such as "big data" and "development of emerging capital markets" were comprehensively analyzed and visualized. The four key visualization legends were used to obtain the status and impact of the utilization of major institutions and big data resources. The focus of research lies in the research of crisis contagion and the development of early warning systems. In addition, this article also outlines the gaps in the overall research direction of academia on financial market risk prevention.
\end{abstract}

\section{Introduction}

The development and operation of the economic market always affect the hearts of the people, and research on this has never stopped. Changes in various links to the financial market or the impact on the financial crisis on the economy are often the core of people's attention. Goldfajn and Valdes (1995) show how the intermediary role of banks has amplified changes in international interest rates and capital inflows, and how this possible volatility has produced an exaggerated business cycle that ultimately led to bank runs, financial and currency collapse [1]. Geert Bekaert and others analyzed the impact of the financial crisis on the stock portfolio of 415 countries and industries from 2007 to 2009. When they found evidence of the spread of the US and global financial sectors, they found that the impact was small; When it comes to a single domestic investment portfolio, its severity is inversely proportional to the quality of the economic fundamentals of each country [2]. Charles Kindleberger [3] pointed out when studying the financial crisis: "Every event is unique to historians." The analysis of data is ubiquitous. With the development of data analysis technology, as Calvo [4] said "If investors think you are not worth it, there will be no capital inflow, so you are not worth it." Market Power promotes the integration of financial markets. The European Monetary Union is the result of financial marketization, and its potential benefits have led to the integration of the stock market [5].

In the era of increasing globalization, big data analysis and data visualization can provide new directions for researchers to achieve the goal of seeing trees and seeing forests.

\section{Data and methods}

This article selects literacy terms related to the research subject from the Oxford bibliography to build a keyword dictionary. Then searched the relevant literature related to economic management, big data, emerging market development and currency from the "Advanced Search" in WoS database [6], and then explained the mapping protocols and strategies as follows:

- TS = ("Economic Management" OR "Big Data" OR "Emerging Market Development" OR "Currency") AND TS = ("Financial Market" OR "Financial Process" OR "Financial Field" OR "Financial Practice" OR "Finance Institutions " OR " Financial Crisis ") AND TS = (" Big Data Technology " OR " Big Data Methods " OR " Complex Data " OR " Potential Big Data Analysis " OR " Data Science " OR " Data Visualization ") AND SU = ( "Business and Economics" OR "Government and Law" OR "Other Social Science Topics" OR "Management" OR "Technology").

As a result, 556 articles were retrieved in February 2020 and mapped using VOSviewer and the Python visualization package.

*Corresponding author. Email: czzzj11@126.com 


\section{Visualization Research Andaper Analysis}

\subsection{Annual Trend}

As shown in Figure 1, the number of citations since 1995 has shown an increasing trend with increasing years. The growth rate has increased sharply from recent years, and the statistical value of the full year has reached a new highest point in 2019. It can be found from Figure 2 that the publications studying this topic have fluctuated since the statistics. That is to say, although the amount of specific citations each year has a big fluctuation significantly, it still shows an overall upward trend.

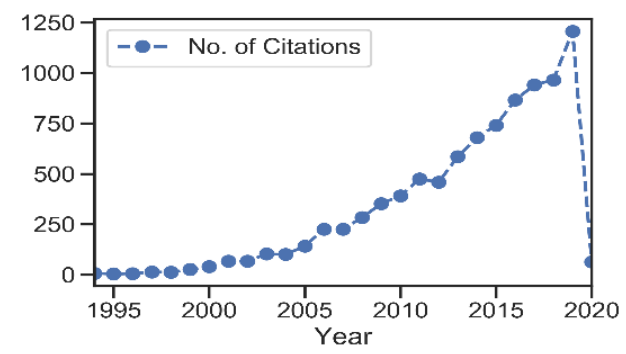

Figure 1. Variation trend of citations

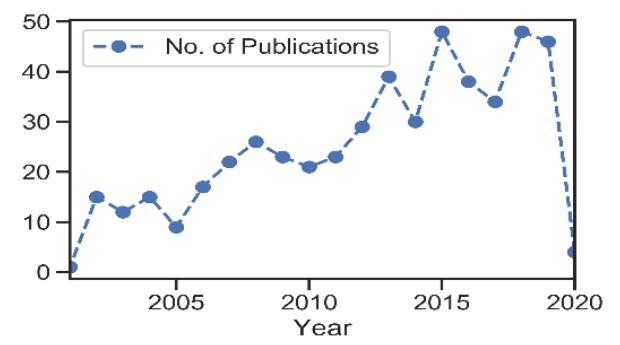

Figure 2. Trends in number of publications

\subsection{WoS categories and research areas}

The classification of WoS is shown in Table 1. The top three are economics, business and finance, and political science. The top three publications account for about two-thirds of the total number of publications, indicating that clusters in related fields of economics, business and finance, and political science are very significant. Other categories include international relations, management, and mathematical methods.

TABLE I. Top WoS categories

\begin{tabular}{lll}
\hline WoS & Quantity & \% \\
\hline Economics & 416 & $48 \%$ \\
Business, Finance & 175 & $20 \%$ \\
Political Science & 36 & $4 \%$ \\
International & 35 & $4 \%$ \\
Relations & 25 & $3 \%$ \\
Business & 23 & $3 \%$ \\
Management & &
\end{tabular}

$\begin{array}{lll}\text { Social Sciences, } & 21 & 2 \% \\ \text { Mathematical } & \end{array}$

Mathematical

Methods

Table 2 lists seven main research areas, each of which contains more than 20 articles. The number one field of business and economics accounts for $70 \%$ of the total number of published papers and is consistent with the number one in the WoS category, which indicates that business and economics have the highest concentration. Other research areas are roughly the same as the WoS category, but the ranking has changed. More diverse research areas have emerged, such as the fifth place in mathematical methods and social sciences and seventh place in WoS. Also, compared to the WoS category, different research areas have emerged, such as government and law.

TABLE II. TOP RESEARCH AREAS

\begin{tabular}{llc}
\hline Research areas & \multicolumn{2}{l}{ Number of articles \% } \\
\hline Business \& Economics & 511 & $70 \%$ \\
Government \& Law & 39 & $5 \%$ \\
International Relations & 35 & $5 \%$ \\
Mathematics & 22 & $3 \%$ \\
$\begin{array}{l}\text { Mathematical Methods In Social } \\
\text { Sciences }\end{array}$ & 21 & $3 \%$ \\
Decial Sciences - Other Topics & 20 & $3 \%$ \\
Others & 20 & $3 \%$ \\
\hline
\end{tabular}

\subsection{Top organizations}

This study analyzed the author's institutional distribution to determine its geographic distribution. Table 3 lists the six organizations that account for more than $5 \%$. The top three are the United States, Germany, and the United Kingdom, with a total share of $55.756 \%$. Among them, it is worth noting that China, as the only developing country in the six major organizations, accounts for $6.475 \%$, second only to the four developed countries: the United States, Germany, Britain, and France. It can be seen that in recent years, China's continuous development has given it a place in the scientific research field of financial markets and economic management. Because of this, this article believes that it is particularly important for China to continue to keep pace with the development of global science and technology and vigorously develop cutting-edge research in this field.

\subsection{Popular Publications}

In the most cited article, Kaminsky GL et al. (1999) point out that economics considers forces in society and nature to be repetitive. History is special, and economics is general. They structured the characteristics of banking and external sector events. It also examines the behavior of macroeconomic indicators emphasized in theoretical 
literature during the crisis [7], which is very similar to Barry Eichengreen (1996b) [8]. In other articles that are more widely used, researchers tend to use research methods that review a certain point of view or establish a model, but few scholars have studied the research trends in the general environment from the perspective of overall research.

\section{5 cluster}

In order to explore the relationship between co-citation and co-citation between concerns and topics in interdisciplinary disciplines, Figure 3 shows a collinear network of 49 author keywords processed by thesaurus compiled by experts. In this article, seven clusters were identified based on the interconnection of the author's keywords. The yellow clusters include keywords such as central bank, exchange rate, and monetary policy. The keywords such as crisis, business cycle, and forecast are important in the green clusters. Blue The clusters include economic growth, hedging, foreign currency debt, cointegration, etc ; the red clusters are composed of words such as commercial capital control, financial markets, and contagion; the big clusters such as big data, early warning systems, and machine learning are important in the purple clusters. The most important keywords of the lake blue clusters are capital flows, emerging markets, etc .; the orange clusters are keywords of financial liberalization, city financial contagion, etc. It can be seen that in the keywords of understanding financial market risk prevention, more articles will be biased towards the crisis facing economic growth and financial markets. When the crisis occurs, it will affect the changes in business cycles and interest rates. And the scope of the crisis can be small or large. Therefore, predicting the crisis has become the theme of today, and it is not difficult to see from the keywords displayed that researchers are inclined to explore the contagion of the crisis and how to establish an early warning system to deal with the crisis. Especially after the 2008 subprime mortgage turmoil in the United States, central banks of all countries have formulated stricter financial forecasting mechanisms and systems to prevent similar incidents from happening again and avoid turbulence in global financial markets.

Figure 4 is the result of the citation source analysis. The figure shows that the major source journal clusters include three major clusters centered on "journal of international money and finance", "journal of banking \& finance", and "economic modeling", and the three are interrelated. Figure 5 shows the distribution and contact status of related research and literature publishing institutions. Among the five colors occupying a prominent position, the red block group represented by the European cent bank is the most prominent. Compared with other ethnic groups, the inter-ethnic connections in this group are the largest and the most closely related. Also, three different color blocks based on "mit", "unic cambridge", and "havard univ" respectively constitute the edge color blocks.

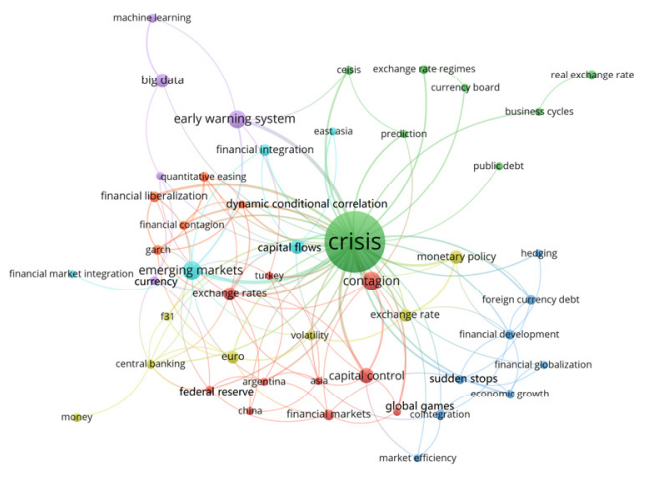

Figure 3 Atlas of Attention Points and Topics

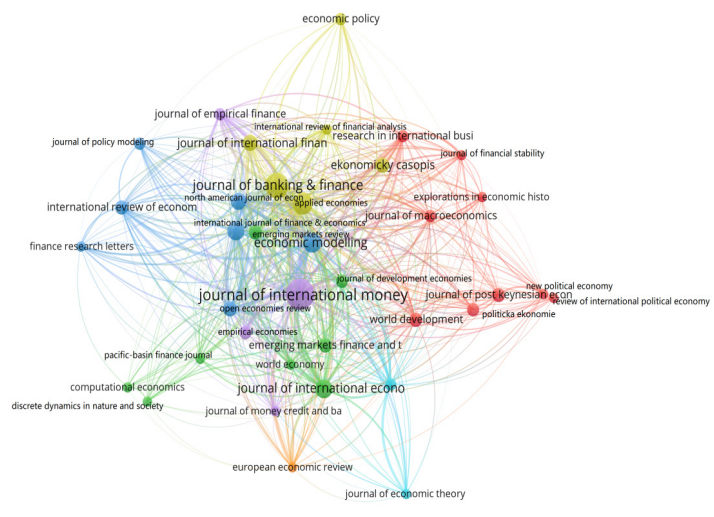

Figure 4 Citation analysis

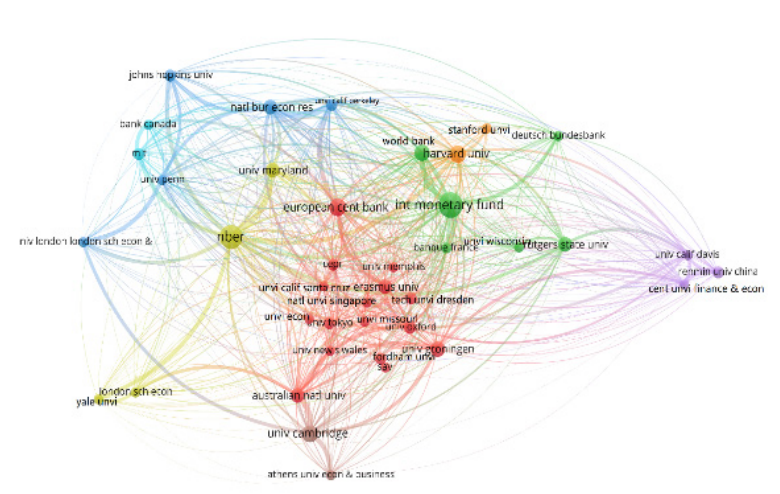

Figure 5 Publishing organization map

It can be seen from Figure 6 that the center of the visualization is the red ethnic group, which is dominated by the United States. It is not difficult to see that the United States is the main research country in the field, and it plays the most important role. From the perspective of cooperative relations, the United States is at the core of the cooperative network, followed by China, Germany, the United Kingdom, France, and Australia. 


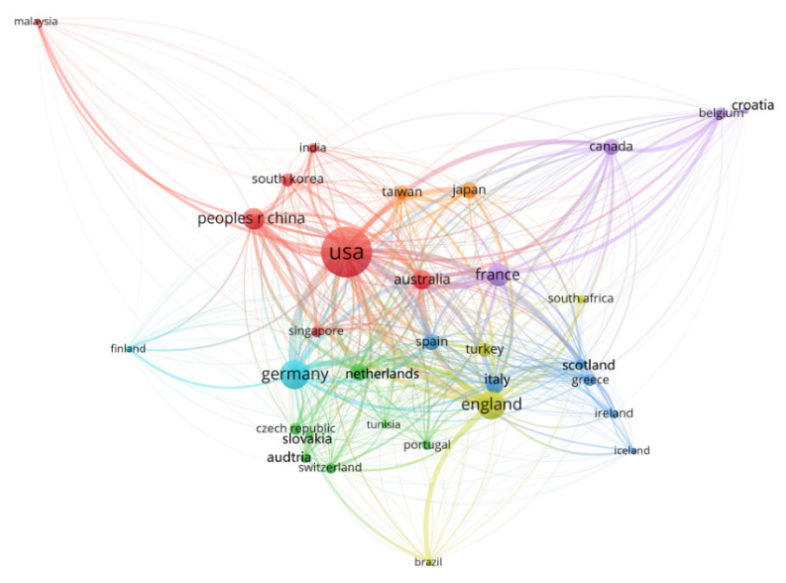

Figure 6 Cooperation map of countries (regions)

\section{Conclusion}

The frenzy of inquiry into the financial market risk has never stopped in academia. A correct and precise direction is the prerequisite for improving research efficiency. This article provides research fronts of research on financial market risk prevention under the background of big data analysis through the analysis of big data and visualization programs. Research and analysis, the current research trend in the academic world, are biased towards the contagion of the crisis and how to establish an early warning system to deal with the crisis, and the developed countries in Europe and the United States have a greater advantage in the use and share of big data resources. Also, China is in this field. The development momentum of China also deserves attention.

\section{References}

1. Goldfajn, Ilan and Valdes, Rodrigo 0. "Balance-ofPayments Crises and Capital Flows: The Role of Liquidity." Mimeo, Massachusetts Institute of Technology, 1995.

2. Bekaert G, Ehrmann M, Fratzscher M, et al. The Global Crisis and Equity Market Contagion [J]. The Journal of Finance, 2014, 69 (6): 2597-2649.

3. Kin delberger, Charles. Manias, panics, and crashes. New York: Basic Books, 1978.

4. Charles Kindelberger (1978 p. 14), in study-ing financial crises, observes: "For historians each event is unique.

5. Kim, SJ, Moshirian, F., \& Wu, E. (2005). Dynamic stock market integration driven by the European Monetary Union: An empirical analysis. Journal of Banking \& Finance, 29 (10), 2475-2502 .

6. Internet Technology -Internet- Oxford Bibliographies-obo.

7. Kaminsky G L, Reinhart C M. The Twin Crises: The Causes of Banking and Balance-of-Payments Problems [J]. American Economic Review, 1999, 89 (3): 473-500.

8. Eichengreen, Barry; Rose, Andrew K. and Wyplosz, Charles. "Contagious Currency Crises." Centre for Economic Policy Research (London) Dis- cussion Paper No. 1453, August 1996a . "Exchange Market Mayhem: The Ante- cedents and Aftermath of Speculative Attacks." Economic Policy, October 1996b, 21 (21), pp. 249-312. 